\title{
OPEN Coupling electro-dewatering and low-temperature air-drying for efficient dewatering of sludge
}

\author{
Hang Lv ${ }^{1,4}$, Oiao Xiong ${ }^{1,4}$, Daoguang $\operatorname{Liu}^{2,3} \& X u \mathrm{Wu}^{1 凶}$
}

This study investigated the effects of electro-dewatering on subsequent low-temperature drying at various potentials and the characteristics of low-temperature air-drying sludge were explored through experiments and multi-physical modeling. Experimental results showed that the extracellular polymeric substance (EPS) content in the sludge was reduced during electro-dewatering process, even the species of organic matter was changed, as well as the dewatered cake tend to form many seepage channels, crack and a certain number of holes. These changes in the properties and structure were conducive to the subsequent low-temperature drying process. For air-drying process, the mass of the sludge cake variation was simulated and results were consistent with the experimental phenomenon. Firstly, the weight of the sludge cake was decreased approximately linearly with time, then tended to stable and reached the dewatering limitation finally. The applied higher electric field intensity $\left(25 \mathrm{~V} \mathrm{~cm}^{-1}\right)$ in the front-end electro-dewatering were conducive to promote water vapor diffusion activity in air-drying stage. Energy consumption and yield analysis results indicated that the combined technology has lower energy consumption and higher yield than that of directly low-temperature drying.

As one of the methods of wastewater treatment, activate sludge process produces large quantities of sludge, which commonly contains over $90 \mathrm{wt} \%$ water content and is difficult to be deep dewatered ${ }^{1-3}$. Especially for China, more than 50 million tonne of municipal sludge and over 40 million tonne of organic industrial sludge with 80 $\mathrm{wt} \%$ water content were produced in $2017^{4}$. Sludge dewatering is a key link in the existing sludge treatment and disposal process ${ }^{5-7}$. Electro-dewatering and air-drying technology can achieve deep sludge-dewatering (water content less than $60 \mathrm{wt} \%$ ) without extra agent addition ${ }^{8,9}$, and have already occupied a certain market share in the existing sludge drying market. However, there are few reports on optimum combination of two technologies, especially the effect of electro-dewatering on subsequent low-temperature drying.

Sludge electro-dewatering technology utilizes electric energy to drive electro-migration of water molecules ${ }^{10,11}$. Recently, it was extensively studied ${ }^{7,12,13}$ and also occupied a certain market share. This technology has some excellent benefits, rapid and efficient dewatering, no agent addition, and relatively low operating costs. However, some problems do exist with this approach, mainly including restricting the development or large-scale application, such as electrode corrosion, ohmic heating (Energy dissipation) and high electric resistance at terminal stage of dewatering (Dewatering limits) ${ }^{14,15}$. It was pointed out that the ohmic heat in sludge electro-dewatering process was the main energy loss ${ }^{16}$, so a large number of literatures reported how to reduce the ohmic heat to avoid sludge temperature increment in electro-dewatering process ${ }^{17,18}$. Optimizing parameters with bench-scale, pilot-scale and industrial-scale experiments, Zhang et al. pointed out that when the anode processing capacity was $41 \mathrm{~kg} \mathrm{~m}^{-2} \mathrm{~h}^{-1}$, energy consumption was controlled at about $70 \mathrm{kWh} \mathrm{t}^{-1}$ sludge, and the sludge water content can be reduced to below $60 \mathrm{wt} \%{ }^{19}$.

Although sludge water content can be reduced to below $60 \mathrm{wt} \%$ by sludge electro-dewatering within $5-20 \mathrm{~min}$, its dewatering limit still restricts further deep dewatering of sludge ${ }^{9,18}$. If the sludge water content was continue to be reduce, the required power consumption would increase dramatically. Low-temperature drying can break through this dewatering limitation and achieve deep dehydration with water content of less than $20 \mathrm{wt} \%{ }^{20}$. However, direct thermal dried from 80 to $20 \mathrm{wt} \%$ of water content will require much more energy consumption, and relatively low space-time yield ${ }^{21,22}$. There were few reports on the effect of sludge low-temperature air-drying

\footnotetext{
${ }^{1}$ School of Environmental Science and Engineering, Huazhong University of Science and Technology, 1037 Luoyu Road, Wuhan 430074, China. ${ }^{2}$ Shanghai Techase Environment Protection Co., Ltd, 1121 North Zhongshan No. 2 Road, Shanghai 200092, China. ${ }^{3}$ College of Environmental Science and Engineering, Tongji University, 1239 Siping Road, Shanghai 200092, China. ${ }^{4}$ These authors contributed equally: Hang Lv and Qiao Xiong. ${ }^{\square}$ email: profxuwu@ hust.edu.cn
} 


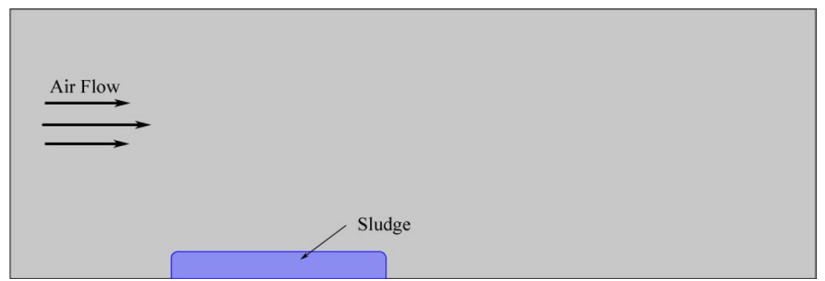

Figure 1. 2D Geometric model.

coupled with electro-dewatering and the impact of the front-end electro-dewatering on the back-end further deep air drying.

In China, the existing sludge dewatering field pays too much attention to the indicators of a single technology, and often overlooks the combined and coordinated operation of the entire treatment route ${ }^{23}$. Previous research work found that biochemical action in the aging process changed the EPS composition properties of the sludge and increased the space-time yield of sludge electro-dewatering to $223.46 \mathrm{~kg} \mathrm{~m}^{-2} \mathrm{~h}^{-124}$. This illustrated that the dehydration characteristics of sludge are closely related to its composition properties ${ }^{25-27}$. The front-end electrodewatering process would also change the composition of the sludge to a certain extent ${ }^{13}$. The sludge was prone to generate ohmic heat and seepage channels (pores) in the electro-dewatering process ${ }^{28}$. If the two approaches were combined for sludge dehydration, it is worth studying whether the front-end electro-dewatering is beneficial to the back-end low-temperature thermal drying.

The model of sludge drying characteristics can provide guidance for the design of sludge drying equipment and the selection of process parameters. Several studies about drying model can be found. Léonard ${ }^{26}$ established models and investigated the influence of drying air velocity, temperature and environmental humidity on sludge drying performance. It was pointed out that temperature of drying air was the main factor affecting the convective drying. Zhang et al. ${ }^{29}$ established sludge drying system theoretical models for heat pump circulation and moist air circulation, and modeling results were validated with the experimental data. Some researchers also introduced thin-layer drying curve models to simulate the electro-dewatered sludge drying curve $e^{30,31}$. However, these models lack the understanding of the time-dependent of sludge air-drying process from perspective of multiphysics and physical geometry. In this paper, the effect of electro-dewatering on subsequent low-temperature drying at various potentials was studied. And this study simulated the time-dependent sludge drying process by introducing porous media model, which considered the air flow field, temperature field, and humidity field comprehensively, and simulated results was validated with low-temperature air-drying experimental data.

\section{Material and methods}

Sludge sample. Sewage sludge sample was acquired from Shayang wastewater treatment plant (Hubei, China). This wastewater treatment plant adopted oxidation ditch technology to treat wastewater, and the sludge sample was mechanically dewatered by belt press filter. All sample was stored at $4{ }^{\circ} \mathrm{C}$ before tests to avoid microbial fermentation after extracting from wastewater treatment plant, and all same group tests were completed within 1 days. Initially the average water content of sludge sample was $81.22 \mathrm{wt} \%$ and $\mathrm{pH}$ was 7.53 .

Experimental set-up. Sludge electro-dewatering experimental test facilities were the same as the previous researches ${ }^{28}$, and the test method for electro-dewatering was also referred to the above approach. The thickness of initial sludge cake was $10.0 \mathrm{~mm}$ (about $50.00 \mathrm{~g}$ ) and electro-dewatered at three different voltage $(15,25,35 \mathrm{~V})$. All testing for electro-dewatering were conducted on high-power electrochemical workstation (CS150, Wuhan Corrtest Instrument Co. Ltd, China; 0-10 A; 0-50 V). For sludge air-drying tests, they were conducted in a constant temperature control box, and the schematic diagram was similar to Fig. 1 . The wind power was provided by a parallel wind electric fan with adjustable speed, and the wind speed can be measured and calibrated with an anemometer. The mass of sludge cake was recorded in real-time through an electronic Bluetooth scale. S-EPS (soluble extracellular polymeric substances) was extracted by centrifugation, the LB-EPS (loosely bound extracellular polymeric substances) and TB-EPS (tightly bound extracellular polymeric substances) contents in sludge were determined by a heat extraction method ${ }^{32}$. The real time water content $(w)$ in sludge was calculated as in the following equation:

$$
w=\frac{w_{0} \cdot m_{s}-m_{t}}{m_{s}-m_{t}} \cdot 100 \%
$$

where $m_{s}$ represents initial mass of sludge, $w_{0}$ is initial water content of sludge, and $m_{t}$ means the real-time mass of water collected or removed water at time $t$.

Analysis methods. Sludge particle size distribution (from 0.1 to $1000 \mu \mathrm{m}$ ) was tested by a laser particle size analyzer (LPSA), BT-9300ST (Bettersize Instruments Ltd., China). Apparent morphological characteristics of the dewatered sludge were observed by a low-vacuum scanning electron microscopy (SEM, TM3030, Japan). All samples were dried by air at room temperature and sputter coated with gold prior to SEM analysis. And parts of the organic species in EPS was examined by three-dimension exaction and emission matrix (3D-EEM) fluores- 


\begin{tabular}{|l|l|l|}
\hline Parameter & Value & Meaning \\
\hline$P_{0}$ & $1 \mathrm{~atm}$ & Ambient pressure \\
\hline$T_{0}$ & $25^{\circ} \mathrm{C}$ & Ambient temperature \\
\hline$u_{0}$ & $1.5 \mathrm{~m} \mathrm{~s}^{-1}$ & Free stream velocity \\
\hline$D_{w a}$ & $2.6^{\star} 10^{-5} \mathrm{~m}^{2} \mathrm{~s}^{-1}$ & Water-air diffusivity \\
\hline$H_{\text {vap }}$ & $44,172 \mathrm{~J} \mathrm{~mol}^{-1}$ & Heat of vaporization \\
\hline$K$ & $1000 \mathrm{~s}^{-1}$ & Evaporation rate \\
\hline$c_{0}$ & $0.51 \mathrm{~mol} \mathrm{~m}^{-3}$ & Initial concentration \\
\hline
\end{tabular}

Table 1. Initial values and some parameters setting for simulation.

cence spectrometer (F-4600 FL Spectrometer, Hitachi, Japan). The above analysis and characterization methods refer to the previous research and literatures ${ }^{33}$.

Numerical modelling. After electro-dewatered, transient change process model of sludge air-drying weight was set up by using COMSOL Multiphysics simulation software (No. 9401017). As shown in Fig. 1, the 2D geometry was built to represent the air-drying scene in the model, which included both sludge and wind field. The initial input parameters of the model were shown in Table 1.

Evaporation in porous media was an important process in sludge air-drying. Many physical effects must be considered: fluid flow, heat transfer and transport of participating fluids and gases. All of these effects were strongly coupled and can be implemented by using the predefined interfaces of COMSOL Multiphysics. The thermodynamic properties of air with water vapor can be described by mixture laws based on the amount of water vapor and dry air. This process was accomplished automatically when moist air was selected as fluid type, and the governing equations was built in the Heat Transfer Module. The concentration $c\left(\mathrm{~mol} \mathrm{~m}^{-3}\right)$ from the transport equation was used as water vapor input. Heat transfer in fluids and sludge cake (porous media) were described as following equations:

$$
\begin{gathered}
\rho C_{p} \frac{\partial T}{\partial t}+\rho C_{p} u \cdot \nabla T+\nabla q=Q \\
\mathrm{q}=-\mathrm{k} \nabla \mathrm{T}
\end{gathered}
$$

$\rho$ (SI unit: $\mathrm{kg} \mathrm{m}^{-3}$ ) was the density.

$C_{p}$ (SI unit: $\mathrm{J} \mathrm{kg}^{-1} \mathrm{~K}^{-1}$ ) was the heat capacity at constant pressure.

$k$ (SI unit: $\mathrm{W} \mathrm{m}^{-1} \mathrm{~K}^{-1}$ ) was the fluid thermal conductivity.

$\mathrm{u}$ (SI unit: $\mathrm{m} \mathrm{s}^{-3}$ ) was the fluid velocity field.

$Q$ (SI unit: $\mathrm{W} \mathrm{m}^{-3}$ ) was the heat source. In this model, the evaporation of water in sludge cake would absorb heat, and Q was calculated in Eqs. (2-4).

$$
\mathrm{Q}=\mathrm{H}_{\mathrm{vap}} \cdot \mathrm{m}_{\mathrm{vap}}
$$

where $H_{\text {vap }}\left(\mathrm{J} \mathrm{mol}^{-1}\right)$ was the latent heat of evaporation, and $\left.m_{\text {vap }}\left(\mathrm{mol} \mathrm{m}^{-3} \mathrm{~s}^{-1}\right)\right)$ was the mass of water evaporated, which was calculated with Eqs. (2-6). For the evaporation process, the evaporated mass of water was added as source term in the transport equation. Evaporation occurred if the concentration of water vapor was below the equilibrium concentration, which was determined by the saturation concentration $c_{\text {sat }}$.

$$
c_{\text {sat }}=\frac{p_{\text {sat }}(T)}{R T}
$$

With the saturation pressure $p_{\text {sat }}$ and the ideal gas constant $\mathrm{R}=8.314 \mathrm{~J} \mathrm{~mol}^{-1} \mathrm{~K}^{-1}$ ).

$$
m_{\text {vap }}=K \cdot\left(c_{\text {sat }}-c\right)
$$

where $K\left(\mathrm{~s}^{-1}\right)$ was the evaporation rate, and $c$ was the current concentration. The evaporation rate depended on the material properties and the process that caused it. This corresponded to the assumption that vapor and liquid was in equilibrium, in other words, the time scale for evaporation was much smaller than the smallest time scale of the transport equations ${ }^{34}$.

The diffusion and migration process of water vapor was described by the following formula.

$$
\begin{gathered}
\nabla \cdot(-D \nabla c)+\boldsymbol{u} \cdot \nabla c=R_{w} \\
R_{w}=m_{\text {vap }}
\end{gathered}
$$

where $D$ represented the water vapor diffusion coefficient, $\boldsymbol{u}$ was velocity of the wet air, and $R$ was the reaction rate, which was actually the water vapor evaporation rate. In sludge porous media, the diffusion rate of water vapor in the moist air gradually slowed down as the water content decreased. In the porous domain, the 

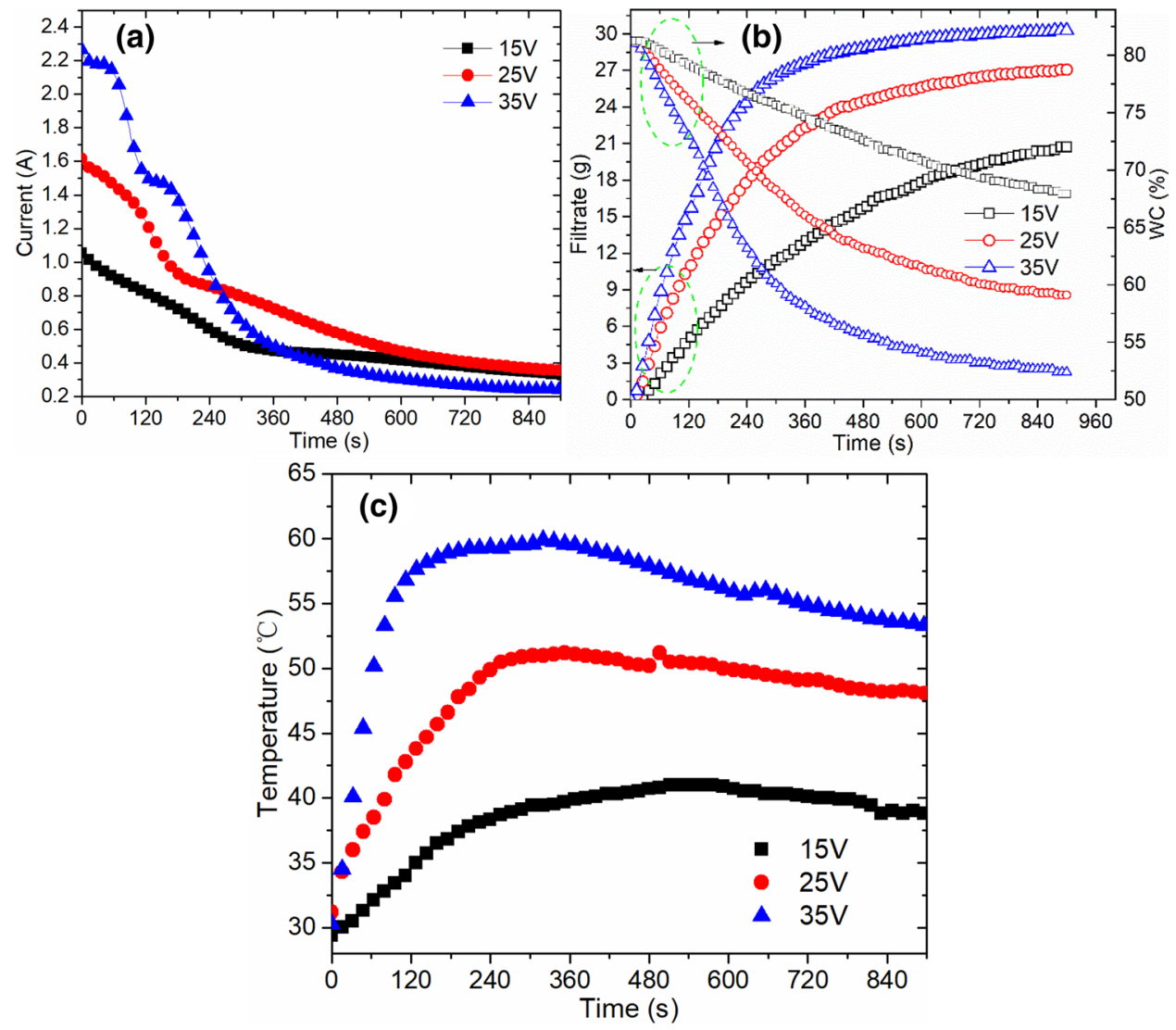

Figure 2. (a) Current, (b) filtrate, and (c) temperature variation in different voltage electro-dewatering process.

\begin{tabular}{|l|l|l|l|l|l|l|}
\hline & $\mathbf{Y}_{70}$ & $\mathbf{Y}_{65}$ & $\mathbf{Y}_{60}$ & $\mathbf{E}_{70}$ & $\mathbf{E}_{65}$ & $\mathbf{E}_{60}$ \\
\hline $15 \mathrm{~V}$ & 59.70 & - & - & 36.47 & - & - \\
\hline $25 \mathrm{~V}$ & 155.64 & 100.75 & 54.79 & 47.14 & 63.81 & 89.99 \\
\hline $35 \mathrm{~V}$ & 279.72 & 188.67 & 133.33 & 58.74 & 79.34 & 95.61 \\
\hline
\end{tabular}

Table 2. Energy consumption and time-space yield by electro-dewatering. $\mathrm{Y}_{70}, \mathrm{Y}_{65}, \mathrm{Y}_{60}$ were represent time-space yield when water content reach 70, 65 and $60 \mathrm{wt} \%$ respectively, unit: $\mathrm{kg} \mathrm{m}^{-2} \mathrm{~h}^{-1}$. $\mathrm{E}_{70}, \mathrm{E}_{65}, \mathrm{E}_{60}$ were represent electric energy consumption per tonne sludge when water content reach 70, 65 and $60 \mathrm{wt} \%$ respectively, unit: $\mathrm{kWh} \mathrm{t}^{-1}$.

diffusivity of water vapor in sludge $\left(D_{e}\left(\mathrm{~m}^{2} \mathrm{~s}^{-1}\right)\right)$ can be adjusted by the diffusivity of water vapor in air $\left(D_{w a}\left(\mathrm{~m}^{2}\right.\right.$ $\left.\mathrm{s}^{-1}\right)$ ) according to the following formula.

$$
D_{e}=D_{w a} \cdot \alpha(w)
$$

where $\alpha(w)$ was the water vapor diffusion activity in the sludge cake, which was the interpolation function obtained in the experiment.

The laminar Navier-Stokes equation was used to model the fluid flow from the air domain. Brinkman equation was used for porous domain, and the Laminar Flow Interface was expanded by enabling porous media domains. The coupling of both flow regimes was done automatically in this way. The resulting velocity field then can be used to model convective heat and species transport.

\section{Results and discussion}

Effect of coupling sludge electro-dewatering and low-temperature air-drying. It can be seen from Fig. 2 that the variation trends of current, filtrate and temperature in the process of sludge electro-dewatering were consistent with the phenomenon observed in the existing literatures. And the dewatering process could be divided into three stages (rapid, slow and limit dewatering stage). In the rapid dewatering stage, the mass of filtrate increased almost linearly with time, then entered the slow dewatering stage, and finally gradually transited to the limit dewatering stage with almost no filtrate. The greater the electric field strength, the lower the final water content in sludge, and more energy consumption was needed (Table 2). For example, under the 

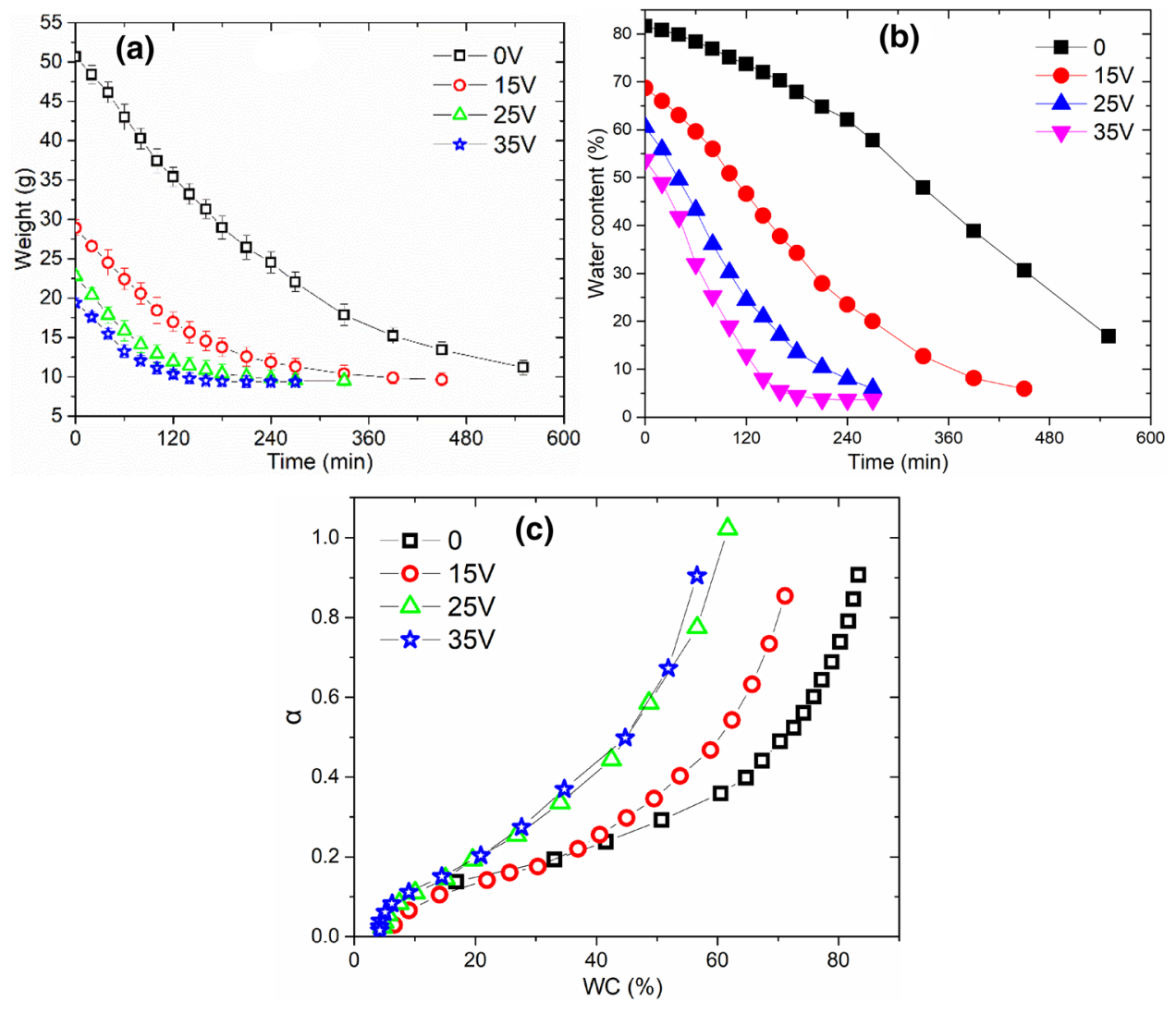

Figure 3. (a) The weight of sludge cake, (b) water content variation during air-dry process and (c) the water vapor diffusion activity in sludge cake (the ratio of the slope of the sludge air-drying curve to the slope of the water-air drying curve under the same conditions).

conditions of $15 \mathrm{~V}, 25 \mathrm{~V}$, and $35 \mathrm{~V}$, the limit of sludge electro-dewatering was reached at about $900 \mathrm{~s}, 700 \mathrm{~s}$ and $500 \mathrm{~s}$ respectively, and the final water content of dewatered sludge cake was $67.92 \mathrm{wt} \%, 59.10 \mathrm{wt} \%$, and 52.36 $w t \%$, respectively. Even if the dewatering time was extended, it was difficult to continue to deepen the degree of dehydration. However, low temperature air drying technology can further dry the sludge. After electro-dewatering, the air-drying mass variation curve of sludge cake was showed at Fig. 3 (Temperature: about $45.0{ }^{\circ} \mathrm{C}$, Relative humidity: about $40.0 \%$ ). It can be seen that the mass of sludge cake decreased rapidly in the early stage, and then as sludge water content reduced, this trend (the air-drying mass of the sludge cake decreased) became more slowly. For example, during the first $120 \mathrm{~min}$ for original sludge $(0 \mathrm{~V})$, air-drying process reduced the mass of the sludge cake by about $15.0 \mathrm{~g}$, and the mass of the sludge cake was only reduced by about $11.0 \mathrm{~g}$ from 120 to $240 \mathrm{~min}$. This phenomenon also existed in electro-dewatered sludge air-drying process. The lower the water content of the sludge, the slower the air-drying mass decline rate. At the same time, air-drying also existed certain limitations. Under current experimental conditions (Temperature: about $45.0^{\circ} \mathrm{C}$, Relative humidity: about $40.0 \%)$, the limit water content of sludge after air-drying was about $5.0 \mathrm{wt} \%$.

After electro-dewatering under different electric field strength conditions, the air-drying water content variation curve of sludge cake was showed as Fig. $3 \mathrm{~b}$ (Temperature: about $45.0^{\circ} \mathrm{C}$, Relative humidity: about $40.0 \%$ ). After a certain intensity of electro-dewatering, the sludge cake was easier to air dry. For example, it took about $300 \mathrm{~min}$ to air-dry the original sludge directly to a water content of $60 \mathrm{wt} \%$. And it also took about $220 \mathrm{~min}$ to realize deep dewatering, which reduced water content of $60 \mathrm{wt} \%$ to $20 \mathrm{wt} \%$ by air drying. However, electrodewatered sludge can be directly air-dried under $25 \mathrm{~V}$, and water content dropped from 60 to $20 \mathrm{wt} \%$. This process took only about $140 \mathrm{~min}$, and $80 \mathrm{~min}$ less than the previous $220 \mathrm{~min}$ of sludge air-drying. When $35 \mathrm{~V}$ voltage was applied for sludge electro-dewatering, it can directly reduce the water content to about $55 \mathrm{wt} \%$ within $15 \mathrm{~min}$, and then air-drying to $20 \mathrm{wt} \%$ water content took about $100 \mathrm{~min}$, while this process (air dried sludge water content from 55 to $20 \mathrm{wt} \%)$ for original sludge $(0 \mathrm{~V})$ need $200 \mathrm{~min}$. Under the same air drying process, it took about $170 \mathrm{~min}$ to dewater sludge with $15 \mathrm{~V}$. It can be seen from Fig. $3 \mathrm{c}$ that the water vapor diffusion activity in sludge cake gradually decreased as sludge water content reduced. Under the same water content, the diffusion activity of electro-dewatered sludge at $25 \mathrm{~V}$ and $35 \mathrm{~V}$ was significantly higher than that of the original sludge. The above phenomenon indicated that higher electric field strength applied for sludge electro-dewatering would be more conducive to improve yield efficiency of subsequent sludge low-temperature air drying.

Changes of sludge EPS after electro-dewatering. Sludge properties may undergo certain changes during electro-dewatering process. Figure 4 showed the difference in sludge extracellular polymer (EPS) con- 

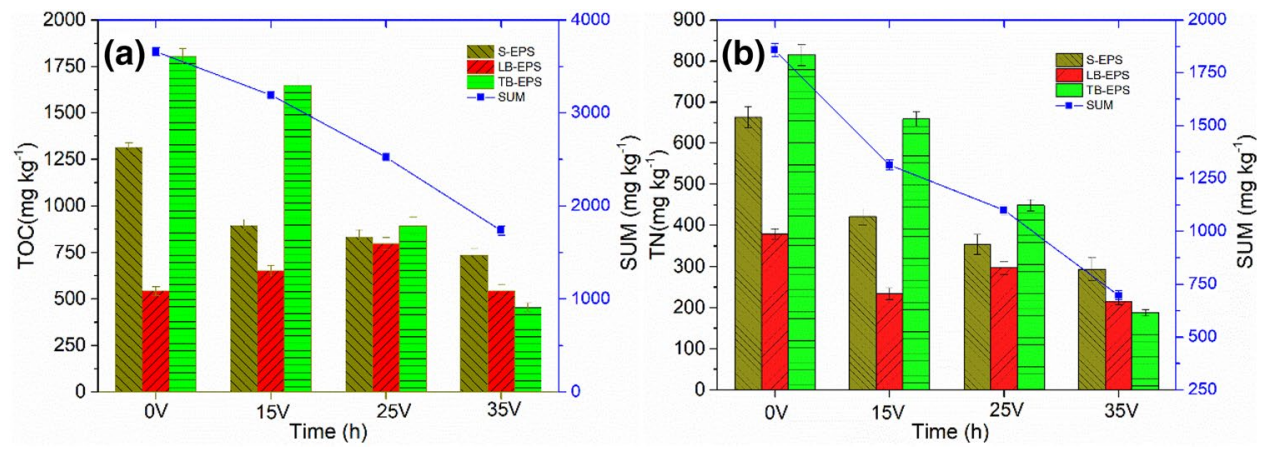

Figure 4. (a) TOC and (b) TN content in sludge after electro-dewatering.

tent for electro-dewatering at different voltages. It can be seen from the Fig. 4 that the total amount of EPS in electro-dewatered sludge decreased continuously with the increasing of the applied electric field intensity. Actually, in the electro-dewatering process, part of the dissolved organic matter in sludge would be transferred to the filtrate along with the water molecules electro-osmotic flow. On the one hand, the increasing of the electric field intensity contributed to more electro-osmotic flow, resulting in an increasing in the amount of water and organic matter removed from sludge; On the other hand, the $35 \mathrm{~V}$ voltage condition would cause some EPS rupturing, leading to more organic matter release into the liquid phase during the electro-dewatering process ${ }^{28}$. The total organic carbon (TOC) content was reduced from about $3661 \mathrm{mg} \mathrm{kg}^{-1}$ of the original sludge to about $1733 \mathrm{mg} \mathrm{kg}^{-1}$ of $35 \mathrm{~V}$ electro-dewatered sludge, and the total nitrogen (TN) content was reduced from about $1857 \mathrm{mg} \mathrm{kg}^{-1}$ to about $697 \mathrm{mg} \mathrm{kg}^{-1}$ of the $35 \mathrm{~V}$ dewatered sludge. Among them, the content of TB-EPS decreased most obviously. As the applied voltage increased, its content gradually decreased from about $1805 \mathrm{mg} \mathrm{kg}^{-1}$ in original sludge to $456 \mathrm{mg} \mathrm{kg}^{-1}$ in the $35 \mathrm{~V}$ electro-dewatered sludge cake, with a decrease of more than $74.00 \%$. As reported in literatures, the bound water content has a strong relationship with TB-EPS ${ }^{36}$. The decrease of TBEPS content may contribute to reducing the binding energy between bound water and sludge flocs, which may be beneficial to subsequent air drying effect.

After a certain voltage of electro-dewatering, not only the EPS content in sludge changed, but also some organic components in the EPS varied. The three-dimensional fluorescence spectrum was performed to analyze organic component in EPS, and results were displayed in Fig. 5. It was obvious that two separate peaks $\mathrm{A}$ and $\mathrm{B}$ appeared in the EPS extracted from original sludge, which were located in the ranges of Ex/Em 240-245/385-390 nm and Ex/Em 280-285/310-315 nm. In the light of literature recorded ${ }^{37}$, these two peaks of organic substance represent Fulvic acid-like and tyrosine and protein-like substance respectively. Electro-dewatering at $15 \mathrm{~V}$, there were still only two peaks A and B appeared in sludge EPS 3D-EEM fluorescence spectrum. Notably, there were 4 peaks appearing at Fig. 5c,d for $25 \mathrm{~V}$ and $35 \mathrm{~V}$ electro-dewatered sludge. Compared with another two Figures (Fig. 5a,b), three new peaks of C, D, and E appeared, and the previous peak A disappeared. This newly appeared peaks of C, D and E were located at Ex/Em 275-280/340-345 nm (Tryptophan), Ex/Em 220-225/310-315 nm (Aromatic Protein I) and Ex/Em 220-225/340-345 nm (Aromatic Protein II) respectively. When applied voltage reached a certain level, the maximum temperature of sludge cake in the process of electrodewatering could exceed $50{ }^{\circ} \mathrm{C}$, which may cause some of the protein or polysaccharides in the EPS to be denatured or decomposed, and even cause some cells to rupture ${ }^{28,38}$. This phenomenon may cause sludge particles to release part of the bound water or reduce the bound energy between water and sludge flocculation particles ${ }^{24,27}$.

Changes of sludge apparent properties after electro-dewatering. It not only caused variation in the composition and content of EPS, but may also lead to changes in internal structure and surface morphology. The surface morphology of the sludge cake after electro-dewatering at different voltages was shown in Fig. 6. It can be seen that the surface morphology of the original sludge was compact, and almost without cracks and voids, which was the same as that of $15 \mathrm{~V}$ electro-dewatered sludge. However, cracks and small holes appeared on the surface of the sludge after $25 \mathrm{~V}$ and $35 \mathrm{~V}$ electro-dewatering. This phenomenon was consistent with the EPS change results in Fig. 5 and the particle size distribution results in Fig. 7. Although the particle size distribution of the original sludge in Fig. 7 was similar to that of the sludge cake after electro-dewatering, there were still some differences between each other. For example, the median particle size of the original sludge and the sludge cake after $15 \mathrm{~V}$ electro-dewatering were $88.56 \mu \mathrm{m}$ and $85.29 \mu \mathrm{m}$, while the median particle size of the sludge cake electro-dewatered by $25 \mathrm{~V}$ and $35 \mathrm{~V}$ was $79.15 \mu \mathrm{m}$ and $74.94 \mu \mathrm{m}$ respectively, a slight decrease compared to the previous two. This phenomenon indicated that when the applied voltage reached a certain degree, some organic matter may be changed under the electric field and the temperature field generated by Joule heat, and some of organic matter flowed out during the electro-dewatering process, which reduced the viscosity of the sludge and make the sludge cake easier to crack. At the same time, a seepage channel was formed. These cracks and small holes structures increased the surface area in contact with air, which was more conducive to subsequent air drying than the compact structure of the original sludge.

Simulation results and key performance indicators analysis. In order to verify the validity of the model, sludge air-drying experiment was carried out at room temperature, and the simulation results for the 

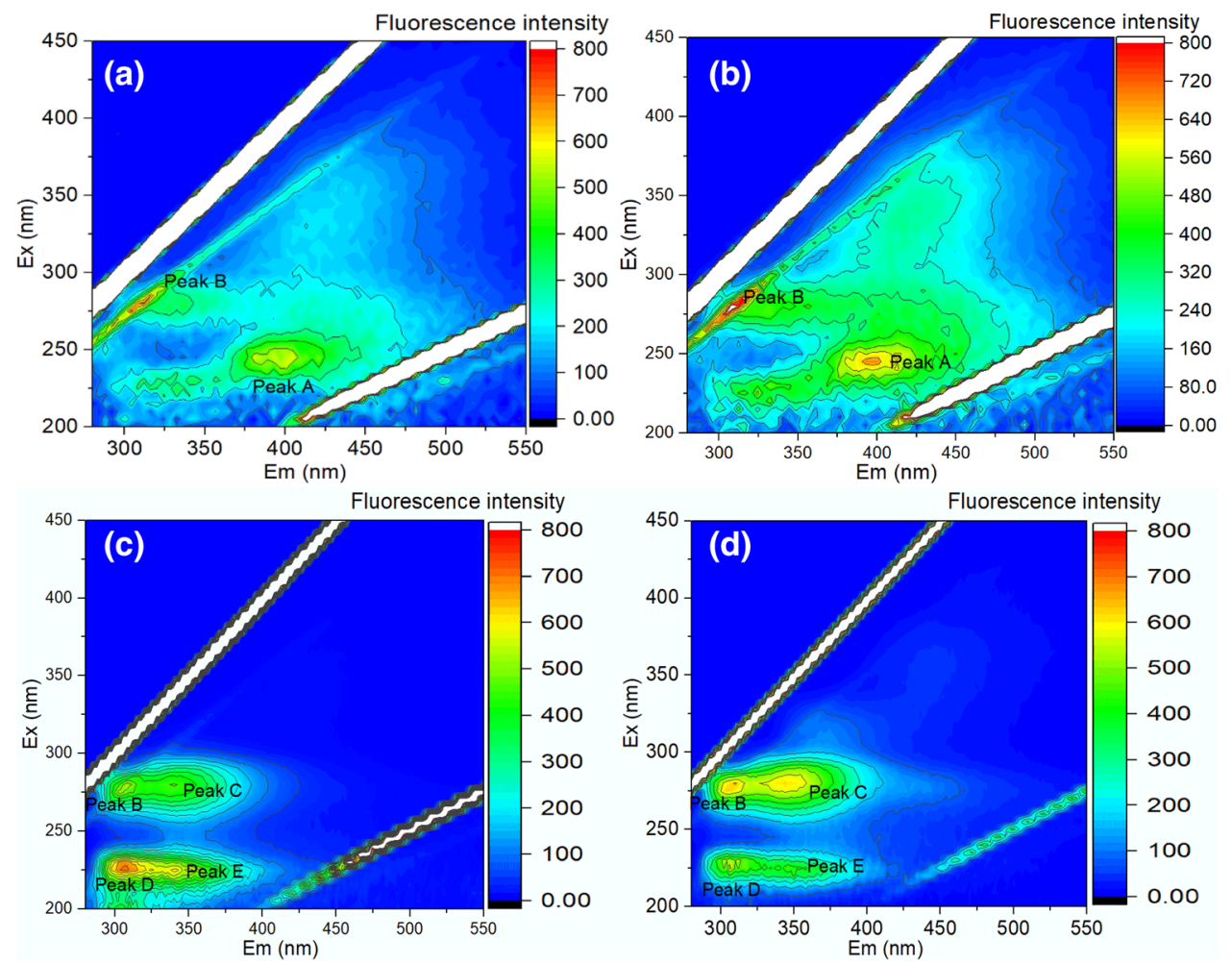

Figure 5. 3D-EEM spectra of EPS extracted from (a) initial sludge and (b) $15 \mathrm{~V}$, (c) $25 \mathrm{~V}$, (d) $35 \mathrm{~V}$ dewatered sludge.
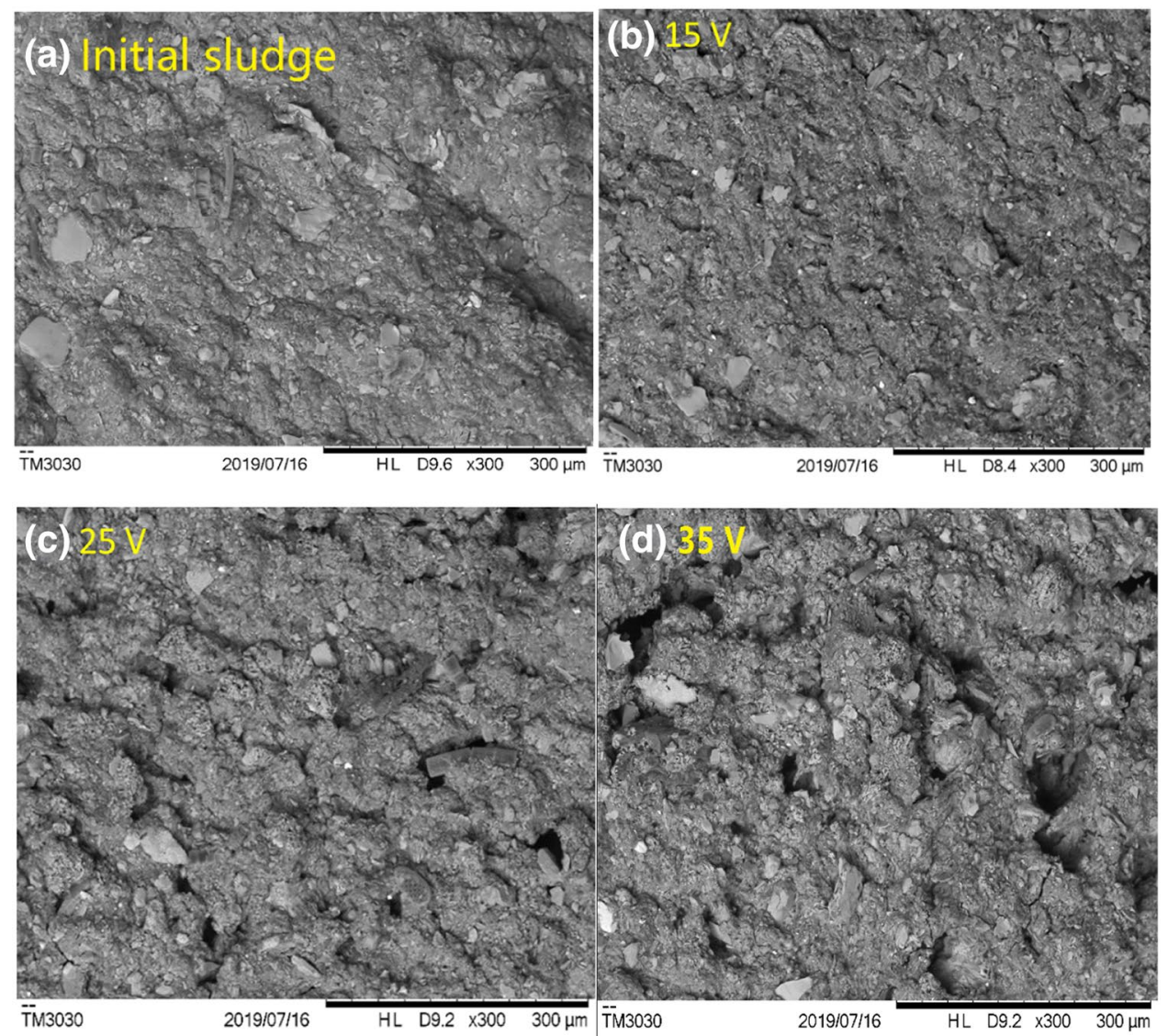

Figure 6. SEM micrographs of electro-dewatering sludge under different voltages. 


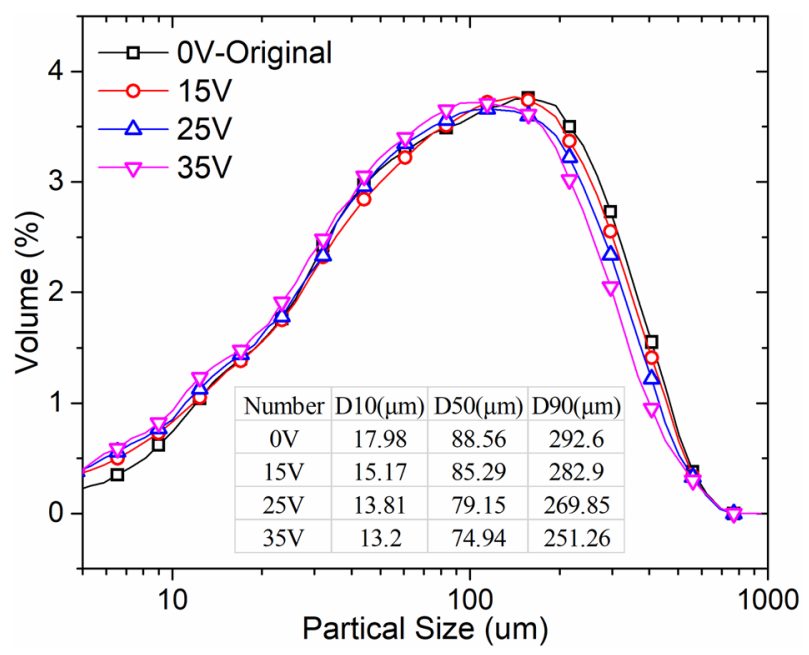

Figure 7. Sludge particle size distribution.
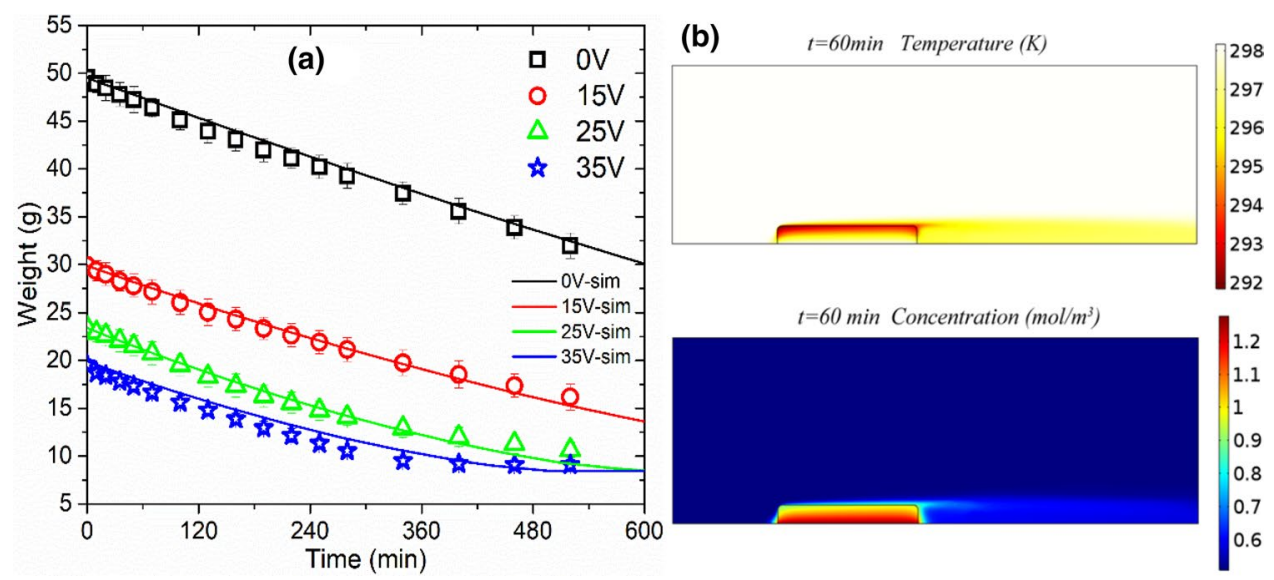

Figure 8. After electro-dewatering, (a) sludge air-drying mass curve, simulated and verified by experiment. (b) Simulated water vapor concentration and temperature distribution at $60 \mathrm{~min}(35 \mathrm{~V})$.

mass of sludge were compared with the experimental data. It can be seen from Fig. $8 \mathrm{a}$ that the simulation results were consistent with the experimental phenomenon. The evaporation of water in the sludge caused the distribution of the temperature field, and the diffusion led to the distribution of the water vapor concentration field (Fig. 8b). The weight of sludge cakes decreased linearly in the early stage, and gradually slowed down in the later stage until it reached the dewatering limit. The linear declined in the early stage, which may be because the water transport rate in the sludge was greater than the evaporation rate. The later nonlinearity stage may be due to the fact that the transport or diffusion rate of water vapor in porous sludge was less than the rate of diffusion into the air. At the same time, it can be observed that the sludge after electro-dewatering was more conducive to the subsequent low-temperature air drying process (sludge air-drying weight and water content decreased faster). In addition, sludge could shrinkage during air-drying process, which would inevitably have a certain impact on the drying efficiency. With the shrinkage of the sludge cake, the diffusion rate of water vapor in the sludge medium would decrease. This factor is described in the model by the molecule diffusion activity $\alpha(w)$.

It can be seen from Table 3 that if one tonne of sludge with water content of $81.22 \mathrm{wt} \%$ was directly air-dried to $10.0 \mathrm{wt} \%$, the required energy consumption was about $292.53 \mathrm{kWh}$. And if the electro-dewatering technology was applied to firstly dewatering to about $60.0 \mathrm{wt} \%$, then the air-drying method was used to dry to $10.0 \mathrm{wt} \%$ water content, the energy consumption was only about $199.94 \mathrm{kWh}$ (Reference energy consumption for thermal drying: $0.40 \mathrm{kWh} \mathrm{kg}^{-1}$, and electro-dewatering E60 in Table 2: $95.61 \mathrm{kWh} \mathrm{t}^{-1}$ sludge). For the analysis of the yield, it took over $550 \mathrm{~min}$ if the sludge directly air-dried from water content of about $81.22 \mathrm{wt} \%$ to $10.0 \mathrm{wt} \%$. And sludge electro-dewatered first to water content of about $60.0 \mathrm{wt} \%$, then air-dried to $10.0 \mathrm{wt} \%$, the total time required was less than $140 \mathrm{~min}$. The less time it took, the more sludge can be processed per unit time. Therefore, it can be found that the combination of electro-dewatering coupled with low-temperature drying technology has advantages in terms of energy consumption and productivity. 


\begin{tabular}{|l|l|l|l|}
\hline Author & Material & Energy consumption//Wh $\mathbf{~ g g}^{-1}$ (based on removed water) & Refs. \\
\hline Zhou et al. & Waste activated sludge & 1.20 & 39 \\
\hline Hong et al. & Waste activated sludge & 0.40 & 40 \\
\hline Eom et al. & Sludge & Over 0.50 & 41 \\
\hline
\end{tabular}

Table 3. Energy consumption by thermal drying in literature.

\section{Conclusions}

Under a certain electric field strength, the EPS content in sludge cake decreased, the species of organic matter also changed during the electro-dewatering process and the dewatered cake tended to form crack and a certain number of holes. Changes in the content and composition of EPS in sludge cake may reduce the binding energy of the bound water, and the cracks and holes formed in sludge cake were beneficial to increase the contact area with the air during the subsequent air-drying process. The simulation results of the model were consistent with the experimental phenomena, indicating that the multi-physical model was suitable for the drying characteristics of electro-dewatering sludge. Taking advantage of the changes in the properties and structure of the sludge cake after the front-end electro-dewatering, followed by low-temperature drying, was more conducive to increasing the space-time yield of the overall sludge treatment and reducing the energy consumption of the overall treatment.

Received: 11 May 2021; Accepted: 8 September 2021

Published online: 27 September 2021

\section{References}

1. Guo, J. \& Zhou, Y. Transformation of heavy metals and dewaterability of waste activated sludge during the conditioning by $\mathrm{Fe}^{2+}$-activated peroxymonosulfate oxidation combined with rice straw biochar as skeleton builder. Chemosphere 238, 124628. https://doi.org/10.1016/j.chemosphere.2019.124628 (2020).

2. Lv, H. et al. Effects of piecewise electric field operation on sludge dewatering: Phenomena and mathematical model. Ind. Eng. Chem. Res. 57, 12468-12477. https://doi.org/10.1021/acs.iecr.8b01019 (2018).

3. Yuan, H., Zhu, N. \& Song, F. Dewaterability characteristics of sludge conditioned with surfactants pretreatment by electrolysis. Bioresour. Technol. 102, 2308-2315. https://doi.org/10.1016/j.biortech.2010.10.065 (2011).

4. China Urban Sludge Treatment and Disposal Technology and Application Advanced Seminar, statistics reports for the China. https://www.aconf.cn/conf_168392.html (2019).

5. Pham, A. T., Sillanpää, M. \& Virkutyte, J. Sludge dewatering by sand-drying bed coupled with electro-dewatering at various potentials. Int. J. Min. Reclam. Environ. 24, 151-162. https://doi.org/10.1080/17480930903132620 (2010).

6. Bian, C. et al. Enhancement of waste activated sludge dewaterability by ultrasound-activated persulfate oxidation: Operation condition, sludge properties, and mechanisms. Chemosphere 262, 128385. https://doi.org/10.1016/j.chemosphere.2020.128385 (2021).

7. Deng, W., Lai, Z., Hu, M., Han, X. \& Su, Y. Effects of frequency and duty cycle of pulsating direct current on the electro-dewatering performance of sewage sludge. Chemosphere 243, 125372. https://doi.org/10.1016/j.chemosphere.2019.125372 (2020).

8. Lv, H. et al. Soluble metal ions migration and distribution in sludge electro-dewatering. Environ. Res. 180, 108862. https://doi.org/ 10.1016/j.envres.2019.108862 (2020).

9. Wu, P. et al. Effect of electric field strength on electro-dewatering efficiency for river sediments by horizontal electric field. Sci. Total Environ. 647, 1333-1343. https://doi.org/10.1016/j.scitotenv.2018.07.464 (2018).

10. Mahmoud, A., Olivier, J., Vaxelaire, J. \& Hoadley, A. F. A. Electrical field: A historical review of its application and contributions in wastewater sludge dewatering. Water Res. 44, 2381-2407. https://doi.org/10.1016/j.watres.2010.01.033 (2010).

11. Yang, Z. et al. Pressurized electro-dewatering of activated sludge: Analysis of electrode configurations (anode). Waste Manag. 81, 157-167. https://doi.org/10.1016/j.wasman.2018.10.001 (2018).

12. Zhang, Y. et al. Optimizing and understanding the pressurized vertical electro-osmotic dewatering of activated sludge. Process Saf. Environ. Prot. 140, 392-402. https://doi.org/10.1016/j.psep.2020.05.016 (2020).

13. Yin, Z., Hoffmann, M. \& Jiang, S. Sludge disinfection using electrical thermal treatment: The role of ohmic heating. Sci. Total Environ. 615, 262-271. https://doi.org/10.1016/j.scitotenv.2017.09.175 (2018).

14. Tuan, P. A., Mika, S. \& Pirjo, I. Sewage sludge electro-dewatering treatment-a review. Drying Technol. 30, 691-706. https://doi. org/10.1080/07373937.2012.654874 (2012).

15. Citeau, M., Loginov, M. \& Vorobiev, E. Improvement of sludge electrodewatering by anode flushing. Drying Technol. 34, 307-317. https://doi.org/10.1080/07373937.2015.1052083 (2016).

16. Navab-Daneshmand, T., Beton, R., Hill, R. J. \& Frigon, D. Impact of joule heating and pH on biosolids electro-dewatering. Environ. Sci. Technol. 49, 5417-5424. https://doi.org/10.1021/es5048254 (2015).

17. Yu, W. et al. Study on dewaterability limit and energy consumption in sewage sludge electro-dewatering by in-situ linear sweep voltammetry analysis. Chem. Eng. J. 317, 980-987. https://doi.org/10.1016/j.cej.2017.02.137 (2017).

18. Wu, P. et al. Dewaterability and energy consumption model construction by comparison of electro-dewatering for industry sludges and river sediments. Environ. Res. 184, 109335. https://doi.org/10.1016/j.envres.2020.109335 (2020).

19. Zhang, S. et al. Novel electro-dewatering system for activated sludge biosolids in bench-scale, pilot-scale and industrial-scale applications. Chem. Eng. Res. Des. 121, 44-56. https://doi.org/10.1016/j.cherd.2017.02.035 (2017).

20. Bennamoun, L., Arlabosse, P. \& Léonard, A. Review on fundamental aspect of application of drying process to wastewater sludge. Renew. Sustain. Energy Rev. 28, 29-43. https://doi.org/10.1016/j.rser.2013.07.043 (2013).

21. Deng, W., Ma, J., Xiao, J., Wang, L. \& Su, Y. Orthogonal experimental study on hydrothermal treatment of municipal sewage sludge for mechanical dewatering followed by thermal drying. J. Clean. Prod. 209, 236-249. https://doi.org/10.1016/j.jclepro.2018.10.261 (2019).

22. Poblete, R. \& Painemal, O. Improvement of the solar drying process of sludge using thermal storage. J. Environ. Manag. 255, 109883. https://doi.org/10.1016/j.jenvman.2019.109883 (2020).

23. Xue, C. et al. Industrialization status, development analysis and incentive policy demands of municipal sludge treatment and disposal industry in china. Water Purif. Technol. 37, 33-39 (2018).

24. Lv, H. et al. The effects of aging for improving wastewater sludge electro-dewatering performances. J. Ind. Eng. Chem. https://doi. org/10.1016/j.jiec.2019.08.049 (2019). 
25. Visigalli, S., Turolla, A., Gronchi, P. \& Canziani, R. Performance of electro-osmotic dewatering on different types of sewage sludge. Environ. Res. 157, 30-36. https://doi.org/10.1016/j.envres.2017.05.015 (2017).

26. Léonard, A., Blacher, S., Marchot, P., Pirard, J. P. \& Crine, M. Convective drying of wastewater sludges: Influence of air temperature, superficial velocity, and humidity on the kinetics. Drying Technol. 23, 1667-1679. https://doi.org/10.1081/drt-200065082 (2006).

27. Lin, F. et al. Effect of extracellular polymeric substances (EPS) conditioned by combined lysozyme and cationic polyacrylamide on the dewatering performance of activated sludge. Chemosphere 235, 679-689. https://doi.org/10.1016/j.chemosphere.2019.06. 220 (2019).

28. Lv, H. et al. Effects of temperature variation on wastewater sludge electro-dewatering. J. Clean. Prod. 214, 873-880. https://doi. org/10.1016/j.jclepro.2019.01.033 (2019).

29. Zhang, T. et al. Theoretical analysis and experimental study on a low-temperature heat pump sludge drying system. Energy 214, 118985. https://doi.org/10.1016/j.energy.2020.118985 (2021).

30. Togrul, I. T. \& Pehlivan, D. Mathematical modelling of solar drying of apricots in thin layers. J. Food Eng. 55, 209-216. https://doi. org/10.1016/S0260-8774(02)00065-1 (2002).

31. Ma, D., Zhu, H., Zhai, J. \& Liu, K. Drying characteristic curve and drying model of electroosmosis dewatering sludge. Chin. J. Environ. Eng. 8, 740-744 (2014).

32. Li, X. Y. \& Yang, S. F. Influence of loosely bound extracellular polymeric substances (EPS) on the flocculation, sedimentation and dewaterability of activated sludge. Water Res. 41, 1022-1030. https://doi.org/10.1016/j.watres.2006.06.037 (2007).

33. Ge, D., Zhang, W., Bian, C., Yuan, H. \& Zhu, N. Insight into a new two-step approach of ozonation and chitosan conditioning for sludge deep-dewatering. Sci. Total Environ. 697, 134032. https://doi.org/10.1016/j.scitotenv.2019.134032 (2019).

34. Halder, A., Dhall, A. \& Datta, A. K. Modeling transport in porous media with phase change: Applications to food processing. J. Heat Transfer https://doi.org/10.1115/1.4002463 (2011).

35. Halder, A., Dhall, A. \& Datta, A. K. An improved, easily implementable, porous media based model for deep-fat frying. Food Bioprod. Process. 85, 220-230. https://doi.org/10.1205/fbp07034 (2007).

36. Sheng, G. P., Yu, H. Q. \& Li, X. Y. Extracellular polymeric substances (EPS) of microbial aggregates in biological wastewater treatment systems: A review. Biotechnol. Adv. 28, 882-894. https://doi.org/10.1016/j.biotechadv.2010.08.001 (2010).

37. Chen, W., Westerhoff, P., Leenheer, J. A. \& Booksh, K. Fluorescence excitation-emission matrix regional integration to quantify spectra for dissolved organic matter. Environ. Sci. Technol. 37, 5701-5710. https://doi.org/10.1021/es034354c (2003).

38. Ge, D., Zhang, W., Yuan, H. \& Zhu, N. Enhanced waste activated sludge dewaterability by tannic acid conditioning: Efficacy, process parameters, role and mechanism studies. J. Clean. Prod. 241, 118287. https://doi.org/10.1016/j.jclepro.2019.118287 (2019).

39. Zhou, J., Liu, Z., She, P. \& Ding, F. Water removal from sludge in a horizontal electric field. Drying Technol. 19, 627-638. https:// doi.org/10.1081/DRT-100103939 (2001).

40. Hong, J., Hong, J., Otaki, M. \& Jolliet, O. Environmental and economic life cycle assessment for sewage sludge treatment processes in Japan. Waste Manag. 29, 696-703. https://doi.org/10.1016/j.wasman.2008.03.026 (2009).

41. Eom, H. et al. Optimization of a hybrid sludge drying system with flush drying and microwave drying technology. Chem. Eng. Res. Des. 148, 68-74. https://doi.org/10.1016/j.cherd.2019.05.058 (2019).

\section{Acknowledgements}

This study was sponsored by The Thousands Youth Talent Project, National Key Research and Development Program of China (No. 2020YFC1908704) and National Natural Science Foundation of China (Nos. 51704122 and 51908233).

\section{Author contributions}

H.L. and Q.X. wrote the main manuscript text. The design and experiments was conducted by H.L. Methods discussing, supervision, document revisions were done by X.W. D.L. take part in some methods discussing and investigation. All authors reviewed the manuscript.

\section{Competing interests}

The authors declare no competing interests.

\section{Additional information}

Correspondence and requests for materials should be addressed to X.W.

Reprints and permissions information is available at www.nature.com/reprints.

Publisher's note Springer Nature remains neutral with regard to jurisdictional claims in published maps and institutional affiliations.

Open Access This article is licensed under a Creative Commons Attribution 4.0 International License, which permits use, sharing, adaptation, distribution and reproduction in any medium or format, as long as you give appropriate credit to the original author(s) and the source, provide a link to the Creative Commons licence, and indicate if changes were made. The images or other third party material in this article are included in the article's Creative Commons licence, unless indicated otherwise in a credit line to the material. If material is not included in the article's Creative Commons licence and your intended use is not permitted by statutory regulation or exceeds the permitted use, you will need to obtain permission directly from the copyright holder. To view a copy of this licence, visit http://creativecommons.org/licenses/by/4.0/.

(c) The Author(s) 2021 